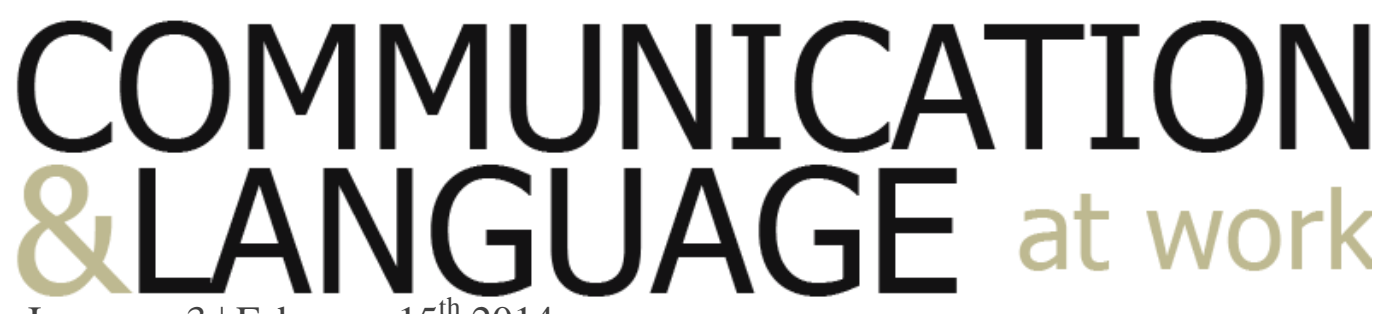

Issue no. 3 | February $15^{\text {th }} 2014$

Social Media and/in Business Communication

\title{
Danish job advertisements: Increasing in complexity
}

Nina L. Walters \& Antoinette Fage-Butler

(pp. 38-52)

http://ojs.statsbiblioteket.dk/index.php/claw/article/view/16556

Subscribe:

http://ojs.statsbiblioteket.dk/index.php/claw/notification/subscribeMailList

Archives:

http://ojs.statsbiblioteket.dk/index.php/claw/issue/archive

Publishing:

$\underline{\text { http://ojs.statsbiblioteket.dk/index.php/claw/about/submissions\#onlineSubmissions }}$

Contact:

http://ojs.statsbiblioteket.dk/index.php/claw/about/contact

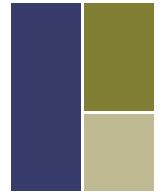

| Bridging Theory and Practice |

http://ojs.statsbiblioteket.dk/index.php/claw 


\title{
Danish job advertisements: Increasing in complexity
}

\author{
Nina L. Walters \\ MA in International Business Communication in English \\ People Coordinator at Insights Denmark \\ Antoinette Fage-Butler \\ Assistant Professor \\ Department of Business Communication, BSS, AU
}

\begin{abstract}
Although job advertisements have developed to incorporate an important array of functions, they are not well understood and there has been little documentation of evolution in the genre (Rafaeli \& Oliver; 1998, 342). The purpose of this article is to address this gap by analysing changes in the genre over time, in this way revealing the background for current practice. Examples of Danish job advertisements for communication positions from 1961, 1991 and 2011 are analysed using Critical Discourse Analysis, and a rich format for job advertisements is developed on the basis of the findings of the analysis and existing theory. The results are likely to be of interest to producers of job advertisements who want a broader knowledge of how this genre with its increasingly complex functionality has evolved and for whom genre features of contemporary job advertising practice is relevant.
\end{abstract}

\section{Keywords}

Diachronic analysis, job advertisements, genre elements, critical discourse analysis 


\section{C ommunication \& Language at Work}

\section{Introduction}

In human resource management literature and organisational communication, job advertisements and their constituting elements have received limited attention, despite the fact that countless job advertisements are published every day. However, the elements of the job advertisement genre are worthy of further attention for two main reasons. First, greater awareness of the genre's elements is valuable as they constantly adapt to accommodate the various time- and context-sensitive functions a job advertisement performs. A second reason why greater understanding of job advertisements is important is because knowledge-based organisations are increasingly concerned that they are effective in attracting and retaining a skilled workforce (Askehave; 2010, 313). Better knowledge of the structure and functions of job advertisements is thus likely to help organisations boost their attractiveness to applicants.

The aim of this study is to map developments in Danish job advertisements' formats for a range of communication-related positions and suggest a rich format for job advertisements which draws on theoretical frameworks and actual practices. This study provides insights into current practices for formats of rich job advertisements and should be useful for practitioners that produce job advertisements.

\section{Methodological Framework}

This study utilises Fairclough's (1995, 2001, 2003, 2008) approach to critical discourse analysis (henceforth CDA) because it is generally recognised as the cornerstone of CDA (Winther Jørgensen \& Phillips; 1999, 72) and because it provides a framework for examining the interplay between linguistic and discursive elements of written communication. The analysis performed as a part of this research project was concerned with Fairclough's textual and discursive dimensions in order to be able to identify and analyse the generic structure and genre elements of job advertisements. According to Fairclough $(2003,71)$, many, but not all, genres are purpose-driven. Those genres which are have a well-defined generic structure; job advertisements can certainly be argued to be one of the purpose-driven genres. According to CDA theory, texts also bear the 


\section{C ommunication \& Language at Work}

imprint of changes in society, such as curricular changes. Given that Fairclough's approach to discourse is one which attends to text as well as context, it provides a methodology that facilitates the analysis of generic structures of job advertisements, and that is sensitive to contextual changes in society. This was advantageous given the diachronic approach to genre taken in this paper.

\section{Theoretical Framework}

Within human resource management literature, job advertisements are not tackled as a generic unit, meaning that one rarely finds information about all the sections that are included in a job advertisement. Mostly, the sections that are highlighted in human resources management literature are only concerned with a narrow description of the advertised job and the perfect applicant, nothing more.

This section thus examines several frameworks for different and discrete sections within job advertisements found in human resource management literature, along with a framework set forth by Rafaeli \& Oliver (1998), which has a holistic approach to job advertisements. These separate frameworks should together provide insights into the complexity of job advertisements which will be useful for the analysis and mapping of developments.

In their research, Rafaeli and Oliver (1998) identify a "skeleton" which most job advertisements have in common. The skeleton consists of four elements: 1) an organisational identity, 2) its human resources needs, 3) information about what is required to fulfil these needs, and 4) information about how to contact the organisation. These elements, according to Rafaeli and Oliver (1998), form the basis of employment advertisements. Job advertisements can, of course, be enriched with additional information about the organisation doing the hiring, such as its values/ culture (Rafaeli \& Oliver; 1998, 345). Employing the skeleton simply serves the formal function of announcing a vacant position and nothing more. Rafaeli and Oliver (1998) argue that the employment of extra descriptive information besides the skeletal elements indicates that job advertisements are an example of organisational discourse with multiple constituents. On this basis, they suggest that job advertisements have two functions, 


\section{C ommunication \& Language at Work}

namely, attracting the 'employment searching public' (which in theory at least can be done by the skeletal elements alone) and impressing a secondary audience, made up of other organisations, the general public and members of the organisation, about the organisation (which is achieved through the inclusion of the additional information).

Rafaeli and Oliver's (1998) skeleton is the only framework which tackles job advertisements as a whole; other frameworks mostly focus on one of the four skeletal elements. Thus, for example, Rafaeli and Oliver's (1998) second element is commonly referred to as the "job description". According to Bratton and Gold (2007) a typical format for a job description contains seven elements which are: 1) job title, 2) department, 3) responsible to, 4) relationships, 5) purpose of job/overall objectives, 6) specific duties and responsibilities and 7) physical/economic conditions (Bratton \& Gold; 2007, 253-254). However, within the field of human resources there is not a universally agreed upon format for job descriptions. This is apparent when looking at Marchington and Wilkinson's (2007) format for job descriptions which shares some of the same elements found in Bratton and Gold's format but with some differences. Their format includes nine elements which are: “1) Job title, 2) location, 3) responsible to, 4) responsible for, 5) main purpose of the job, 6) responsibilities/duties, 7) working conditions, 8) other matters and 9) any other duties" (Marchington \& Wilkinson; 2007, 167). The last two elements are where this format stands out. These elements allow the provision of additional information such as details about performance standards, requirements and geographic mobility as well as extra information about additional duties the new employee might be expected to perform.

The third element in Rafaeli and Oliver's (1998) skeleton called “information about what is required to fulfil these needs" can be argued to constitute what other theorists have referred to as "personnel specification", because, among other things, it relates to information about what qualifications are required of the applicant. There are two longstanding approaches to such personnel specifications. They are Rodger's seven-point plan from 1952 and Fraser's five-fold grading system from 1966 which have adapted some of the aspects from Rodger's approach (Marchington \& Wilkinson; 2007, 169). Rodger's seven-point plan contains the following seven elements: 1) Physical make-up, 2) Attainments, 3) General intelligence, 4) Special aptitudes 5) Interests, 6) Disposition, 
7) Circumstances (Cushway; 2005, 10-11). Fraser's approach can be seen as a condensed version of Rodger's seven-point plan, containing only five elements: 1) Impact on others, 2) Qualification and experience, 3) Innate abilities, 4) Motivation and 5) Adjustment (Bratton \& Gold; 2007, 255). Generally, the first three elements in the two approaches cover the same human attributes. It is only in the last two elements that Fraser's approach differs noticeably from Rodger's approach. Fraser shies away from elements like Rodger's fifth and seventh elements, the latter of which is called circumstances and focuses on special demands for age, sex and domestic ties. Fraser's fourth and fifth elements (motivation and adjustment), on the other hand, describe applicants' desire to succeed, their commitment to achieving their goals, their emotional stability and ability to cope with stress, all of which to some extent are covered by Rodger's sixth element called disposition.

From this literature review, it can be argued that Rafaeli and Oliver's (1998) four skeletal elements function as overall sections in job advertisements, as this approach to the elements of job advertisements subsumes elements from the aforementioned "job descriptions" and "personnel specifications".

These four skeletal elements thus form the main theoretical basis of this paper.

\section{Data description and research design}

This study employs a diachronic approach, looking at communication job advertisements from three years $(1961,1991$ and 2011) to map developments in the genre over time. A combination of two sampling strategies was used to collect the job advertisements, which were subsequently analysed. These were criterion sampling (Patton; 2002) and maximum variation sampling (Ibid). First of all, criterion sampling was used to cast the net wide and collect a substantial number of job advertisements.

Five criteria were used during the criterion sampling phase:

1. Job advertisements for communication positions from the years 1961, 1991 and 2011. The intervals between the dates were considerable in order to allow for possible changes in the genre conventions, structure and format of the job advertisements to take hold and be more prominent. 


\section{C ommunication \& Language at Work}

2. Job advertisements from the two national Danish newspapers Berlingske Tidende and Politiken as well as from the online source Jobindex.dk for 2011. The reasoning behind including an online source was because there was a significant decline in job advertisements published in newspapers in 2011 compared to the previous two dates.

3. Job advertisements sourced from the months of August, September and October. These are the three months immediately after the summer holidays in Denmark and the months where most graduates are looking for their first job.

4. Job advertisements sourced from the weekdays Wednesday and Sunday. These were traditionally the two days of the week where the majority of job advertisements were published.

5. Job advertisements for full-time positions only.

The five criteria are shown in Table 1 below along with the number of job advertisements found that fulfilled the above mentioned criteria.

Table 1: Danish Communication Job Advertisements 1961, 1991 and 2011

\begin{tabular}{|c|c|c|c|c|c|}
\hline Year & Month & $\begin{array}{c}\text { Berlingske } \\
\text { Tidende }\end{array}$ & Politiken & Jobindex & Total \\
\hline $\mathbf{1 9 6 1}$ & August, & 50 & 16 & & \multirow{1}{*}{169} \\
& September, & 49 & 6 & & \\
& October & 41 & 7 & & \multirow{2}{*}{53} \\
\hline $\mathbf{2 0 9 1}$ & August, & 22 & 7 & & \\
& September, & 12 & 3 & & 39 \\
& October & 8 & 1 & & \\
\hline
\end{tabular}

261 job advertisements were found using the criterion sampling strategy. The next strategy to be used was maximum variation sampling which "aims at capturing and describing the central themes that cut across a great deal of variation" (Patton; 2002, 234-235). This sampling strategy includes typical and extreme cases and other identified positions, which means that any shared characteristics found in the sample are derived out of heterogeneity. Maximum variation sampling was used to reduce the pool 


\section{C ommunication \& Language at Work}

of 261 collected job advertisements to a sample size of nine job advertisement which are illustrative of the pool as a whole, three representing each of the chosen years. The nine job advertisements were selected on the basis of three size dimensions (see Table 2). One advertisement for each size for every year was chosen, ensuring that the final corpus captured as much variation on the parameter of length as possible. The parameters for each of the three years were modified as the size of job advertisements changed dramatically over time: what constituted a large job advertisement in 1961 was not a large job advertisement in 2011. These parameters are illustrated in more depth in the following table.

Table 2: The three dimensions defined by word count

\begin{tabular}{|c|c|c|c|}
\hline & $\begin{array}{c}\text { small job } \\
\text { advertisement }\end{array}$ & $\begin{array}{c}\text { medium job } \\
\text { advertisement }\end{array}$ & $\begin{array}{c}\text { large job } \\
\text { advertisement }\end{array}$ \\
\hline 1961 & less than 20 words & $\begin{array}{l}\text { more than } 20 \text { words, } \\
\text { less than } 50 \text { words }\end{array}$ & more than 50 words \\
\hline 1991 & less than 60 words & $\begin{array}{l}\text { more than } 60 \text { words, } \\
\text { less than } 140 \text { words }\end{array}$ & more than 140 words \\
\hline 2011 & less than 200 words & $\begin{array}{c}\text { more than } 200 \text { words, } \\
\text { less than } 500 \text { words }\end{array}$ & more than 500 words \\
\hline
\end{tabular}

The nine job advertisements that were collected on the basis of the combination of criterion and maximum variation sampling were analysed using CDA (Fairclough; 1995, 2001, 2003, 2008). In addition, Rafaeli and Oliver's (1998) skeleton was used as a reference point during the analysis of the generic structure of the nine job advertisements and for defining the specific genre sections and elements that were present: these are illustrated in Table 3 below.

\section{Results and discussion}

The many similarities and differences found in the generic structure of the nine analysed job advertisements across the three years are highlighted in the following table. The table illustrates whether an individual element identified in the job advertisements occurs in each of the three examined years. The table provides an overview of which elements were characteristic for each year and whether there was an increase or decline 
C ommunication \& Language at Work

in the use of a specific generic element. An element can maximally occur once for each job advertisement, meaning a maximal of three occurrences per year.

Table 3: Changes and developments in the contents of the examined job advertisements

\begin{tabular}{|c|c|c|c|c|}
\hline Sections & Element & 1961 & 1991 & 2011 \\
\hline \multirow{5}{*}{$\begin{array}{l}\text { Organisational } \\
\text { identify }\end{array}$} & Company name & II & III & III \\
\hline & Field of occupation & I & III & I \\
\hline & Culture \& values & & I & I \\
\hline & Expected growth/Financial status & & & II \\
\hline & Company size (number of employees) & $\mathrm{I}$ & II & III \\
\hline \multirow{7}{*}{$\begin{array}{c}\text { Job } \\
\text { description }\end{array}$} & Job title & III & III & III \\
\hline & Location department & II & I & II \\
\hline & Responsible to & $\mathrm{I}$ & II & $\mathrm{I}$ \\
\hline & Responsible for & & I & I \\
\hline & Main purpose of job & & I & I \\
\hline & Responsibilities/Duties & & III & III \\
\hline & Economic and physical working conditions & $\mathrm{I}$ & III & $\mathrm{I}$ \\
\hline \multirow{8}{*}{$\begin{array}{c}\text { Personnel } \\
\text { specification/ } \\
\text { requirements }\end{array}$} & Physical make-up & & & \\
\hline & Attainments/Qualifications and experience & III & III & III \\
\hline & Disposition & & I & III \\
\hline & General intelligence/Innate abilities & I & & \\
\hline & Special aptitudes & $\mathrm{I}$ & II & I \\
\hline & Adjustments & & I & \\
\hline & Circumstances & III & $\mathrm{I}$ & \\
\hline & Interests & & & \\
\hline \multirow{6}{*}{$\begin{array}{c}\text { Practical } \\
\text { information }\end{array}$} & Application deadlines & & & II \\
\hline & Date the position is to be filled & III & & $\mathrm{I}$ \\
\hline & When interviews are being held & & & $\mathrm{I}$ \\
\hline & $\begin{array}{l}\text { Recruitment process contracted out to another } \\
\text { company }\end{array}$ & & & I \\
\hline & Contact information for recruitment company & & & I \\
\hline & $\begin{array}{l}\text { Availability of follow up/Extra information } \\
\text { offered }\end{array}$ & & I & I \\
\hline $\begin{array}{c}\text { Contact } \\
\text { information }\end{array}$ & $\begin{array}{l}\text { Company address, e-mail, phone number et } \\
\text { cetera. }\end{array}$ & II & III & III \\
\hline
\end{tabular}




\section{C ommunication \& Language at Work}

Analysis reveals that there are four types of developmental changes in the content of job advertisements. The first type relates to elements that do not develop or change but are consistent and occur in all job advertisements for all three years. These elements are company name, job title, requirements for educational qualifications and experience and lastly contact information. This was not a surprising discovery given that Rafaeli and Oliver (1998) considered them foundational in any job advertisement. This finding provides supporting evidence of the on-going value of their theory.

The second type involves elements which have ceased to be used. A good example of this is the element called circumstances that comprised requirements such as age, domestic ties, mobility, and unsocial work hours. This element was widely used in job advertisements from 1961 because gender and age requirements in job advertisements were common practice, but as can be seen in the table above, this element was not used at all in 2011 due to the implementation of the Equal Treatment Act in Denmark in 1978 which led to prohibition of gender-based job advertisements (Gyldendals; 2010).

The third type of development covers elements which are new and only appear in 1991 and 2011. Elements such as organisational culture \& values and financial status of the company fall under this type of development. They are also examples of elements that serve as tools for impression management. Other elements such as responsibilities/duties and main purpose of job also start occurring in the last two years examined. According to Feldman et al. (2006), these elements have become more widely used in later years because they boost the perceived attractiveness of a vacant position.

The final type of development suggests a movement away from Rodger's seven point plan for personnel specifications from 1952 because elements he suggests, such as physical make-up and interests, do not appear at any point in the nine analysed job advertisements. As job advertisements have tended to accumulate rather than to drop elements, omission of this element in the current data-set is significant. It suggests that these are no longer considered relevant and/or appropriate in current job advertisements, suggesting greater focus on professionalism in more recent advertisements. 


\section{C ommunication \& Language at Work}

As indicated in the Introduction, an aim of this research project was to map developments within the job advertisement format and on that basis suggest a format for current job advertisements that may be valuable for human resource managers. In Table 4 , a format is presented which is informed by the mapping of the developments above and inspired by elements from Rafaeli \& Oliver's (1998) skeletal framework, Bratton \& Gold's (2007) and Marchington \& Wilkinson's (2007) formats for job descriptions, Fraser's five-fold grading system and Rodger's seven-point plan for personnel specifications, which were also used during the analysis of the job advertisements to identify the various aspects of the genre. Awareness of these aspects was valuable as it made it possible to identify new elements on the basis of the analysis.

A suggested format is thus created for rich job advertisements. It contains six principal areas that can be argued to be the foundation of contemporary rich job advertisements. On the basis of the findings of this paper and informed by existing theory, each of the six principal areas has one or more descriptive sub-headings which illustrate the type of information that the specific principal area can contain. The descriptive sub-headings are included in this suggested format for rich job advertisements either on the basis of their continual occurrence in the analysed job advertisements or because they were present in some of the job advertisements from 2011. The significance of elements appearing in job advertisements from 2011 is that they might be indicative of the beginning of new trends within job advertisements. This is why the element called recruitment process contracted out to another company is included in the suggested format despite the fact that it only appears in one of the job advertisements from 2011. 
Communication \& Language at Work

Table 4: Format for job advertisements

Title

\begin{tabular}{|c|c|}
\hline \multirow{6}{*}{ Organisational Identity: } & Company name \\
\hline & Field of occupation \\
\hline & Culture and values \\
\hline & Organisational history \\
\hline & Financial status \\
\hline & Company size (number of employees) \\
\hline \multirow{7}{*}{ Job description: } & Job title \\
\hline & Location/Department \\
\hline & Responsible to \\
\hline & Responsible for \\
\hline & Main purpose of job \\
\hline & Responsibilities/Duties \\
\hline & Economical and physical working conditions \\
\hline $\begin{array}{l}\text { Personnel } \\
\text { specifications: }\end{array}$ & $\begin{array}{l}\text { Educational qualifications and experience } \\
\text { Disposition } \\
\text { Special aptitudes }\end{array}$ \\
\hline \multirow{6}{*}{ Practical information: } & Application deadlines \\
\hline & Date the position is to be filled \\
\hline & Week interviews are being held \\
\hline & Recruitment process contracted out to another company \\
\hline & Contact information for the HR recruitment company \\
\hline & Availability of follow up/Extra information offered \\
\hline Contact information: & Company address/E-mail address/Phone number \\
\hline
\end{tabular}

\section{Conclusion}

This paper has conducted a discourse analysis of job advertisements over three separate years (1961, 1991 and 2011), documenting changes in the genre over time. It contributes both empirically and theoretically to understandings of the genre of job advertisements. Discourse analysis shows the ways in which job advertisements provide 


\section{C ommunication \& Language at Work}

information about vacant positions as well as what discursive means are used to impress secondary audiences. Theoretically, the paper contributes to better understandings of the genre elements of job advertisements. It indicates the on-going validity of work by Rafaeli and Oliver (1998), as well as showing where changes are taking place in relation to Rodger's (1952) seven-point plan for 'personnel specifications'. Additionally and significantly, it identifies newer elements which do not appear in any of the reviewed literature.

The limitations of the paper point to areas for future research. First of all, this paper has used Danish advertisements only, so one cannot generalise the findings to job advertisements written in other contexts. This suggests the value of future comparative studies. Furthermore, using a larger data set would be advantageous, as it would help to ensure that the patterns found in the nine job advertisements and that provide the basis of the proposed format for rich job advertisements is as reflective as possible of current trends. Moreover, just as this paper has revealed the time-sensitivity of the genre, there needs to be continued research into this genre to follow on-going changes. This paper reveals that the formats of job advertisements are constantly under development which means that the suggested format in this paper is at best valuable for job advertisements written now and in the near future: in keeping with what this paper attests, new functions are likely to be included in this genre over time, and others will probably be lost. This paper presents a model of the key elements found in job advertisements; it is derived from a discourse analysis of existing examples of the genre, as well as being informed by theory. It would, however, be advantageous to get feedback on the usefulness of the model from companies/institutions, job-seekers and the general public. Finally, it would be useful to focus more on the macro-discourses that are prevalent in job advertisements. Here, inspiration is to be had from research into critical genre theory, such as Bhatia (2010) who identifies the macro-discourses in corporate annual reports. In this way, light can be shed on how professional discourse used to communicate with a wide public reflects and deploys the discourses that circulate in society.

In sum, this paper illustrates how the genre of the job advertisement has developed over the last 50 years, as well as indicating what features of the genre characterise the richer 


\section{Communication \& Language at Work}

job advertisements written today. We hope that the research presented here sheds light on an important but under-investigated genre that contributes not only to academic understandings of the genre, but also provides insights that are considered valuable by the professionals who produce job advertisements.

\section{Authors}
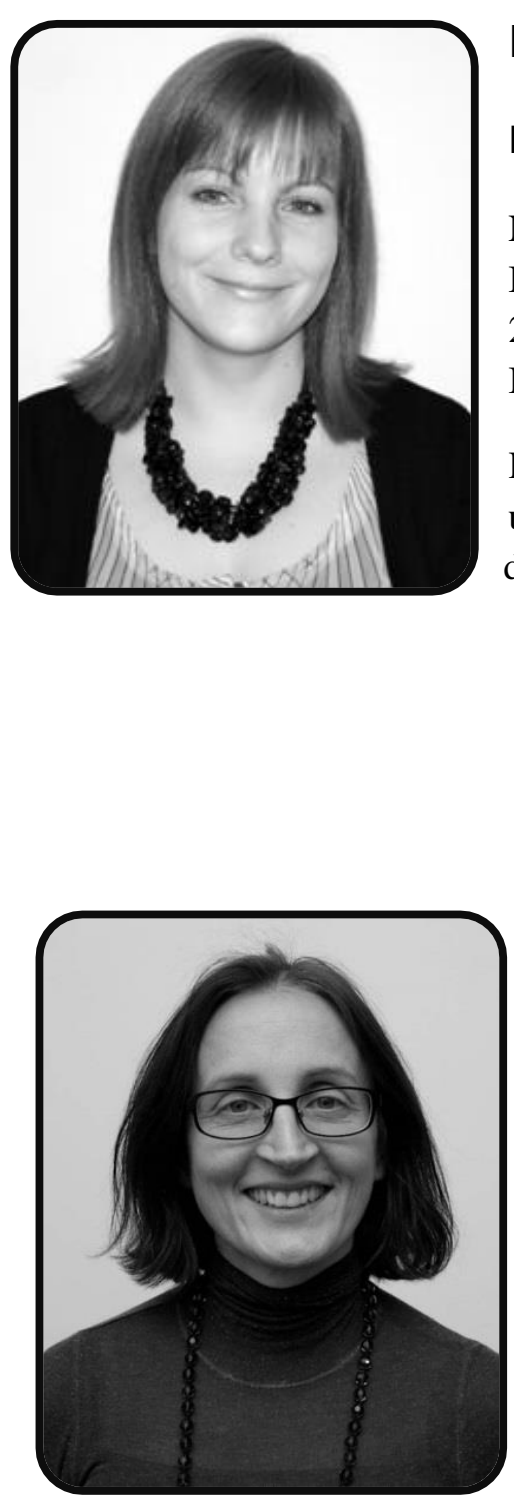

Nina Louise Walters

People Coordinator, Insights Denmark, Aarhus

Nina Louise Walters is Master of Arts graduate in International Business Communication in English from Aarhus University 2013. She is currently employed as a People Coordinator at Insights Denmark.

Her academic interests includes human resources in particular the use of personal profiling for personal-, team- and leadership development as well as recruitment.

\section{Contact:}

Email: walters18n1@hotmail.com

\section{Antoinette Fage-Butler}

Assistant Professor, Department of Business

Communication, School of Business and Social Sciences, Aarhus University

Antoinette Fage-Butler holds a $\mathrm{PhD}$ in Knowledge Communication from Aarhus University, Denmark, where she is currently an assistant professor. Her research interests include online health communication, improving quality in texts for patients, and ethical aspects of health communication. She is involved in a number of international collaborations, and contributes to the development of poststructuralist approaches to discourse and critical genre analysis.

\section{Contact:}

Email: fage-butler@asb.dk

Address for correspondence: Department of Business Communication, Jens Chr. Skous Vej

4, Building 1481; Room 633, School of Business and Social Sciences, Aarhus University,

8000 Aarhus C, Denmark.

Danish job advertisements: Increasing in complexity 


\section{Bibliography}

Askehave, Inger. 2010. Communicating leadership. Journal of Business Communication 47 (3): 313.

Bratton, John, and Jeffrey Gold. 2007. Human resource management: Theory and practice. 4. ed. Basingstoke: Palgrave Macmillan.

Bhatia, V. K. 2010. Interdiscursivity in professional communication. Discourse \& Communication 4 (1): 32-50.

Cushway, Barry. 2005. Employer's handbook: An essential guide to employment law, personnel policies and procedures. 3. ed., London: Kogan Page.

Fairclough, Norman. 2008. Discourse and social change. Cambridge: Polity Press.

. 2003. Analysing discourse: Textual analysis for social research. London: Routledge.

Fairclough, Norman,1941-. 2001. Language and power. Language in social life series. 2. ed. Harlow: Longman.

1995. Critical discourse analysis: The critical study of language London: Longman.

Feldman, Daniel C., William O. Bearden, and David M. Hardesty. 2006. Varying the content of job advertisements: The effects of message specificity. Journal of Advertising 35 (1): 123.

Gyldendals. 2010. Ligestilling - arbejdsretlige aspekter [Equality - labor law aspects]. Accessed 01-02-2013 at webpage address: http://www.denstoredanske.dk/Samfund\%2c_jura_og_politik/Samfund/Kvindesage $\mathrm{n} /$ ligestilling/ligestilling_(Arbejdsretlige_aspekter)

Marchington, Mick, and Adrian Wilkinson. 2007. Human resource management at work: People management and development. 3. ed., London: Chartered Institute of Personnel and Development.

Patton, Michael Quinn. 2002. Qualitative research and evaluation methods. 3. ed. Newbury Park: Sage.

Rafaeli, Anat, and Amalya L. Oliver. 1998. Employment ads. Journal of Management Inquiry 7 (4): 342. 
Issue no. \#

C ommunication \& Language at Work

Winther Jørgensen, Marianne, and Louise Phillips. 1999. Diskursanalyse som teori og metode. 1. udgave ed. Frederiksberg: Samfundslitteratur. 